\title{
Differential Equations Applied to Photopyroelectric Detection
}

\section{Equações Diferenciais em Detecção Fotopiroelétrica}

DOI: $10.46814 / \operatorname{lajdv3n6-007}$

Recebimento dos originais: 01/10/2021

Aceitação para publicação: 12/11/2021

Gloria Maria Conde Lima

Degree in Mathematics

Bragança Radio Education System, Praça das Bandeiras, Bragança, PA, Brazil

E-mail: gloriaconde200910@gmail.com

Marcos Lazaro de Souza Albuquerque

Doctor of Science

Federal University of Pará, Bragança Campus, Leandro Ribeiro St, Braganca, PA, Brazil

E-mail: mlazaro@ufpa.br

\begin{abstract}
The present research aimed to study the technique of photopyroelectric detection, it is specifically setting SPPE. Besides performing graphics simulations analytical amplitude and phase of the thermal signal due to the modulation frequency generated to obtain ownership for a sample thermal diffusivity of vegetable oil.
\end{abstract}

Keywords: ppe detection, vegetable oil.

\section{RESUMO}

O presente trabalho de pesquisa teve como objetivo estudar a técnica de Detecção Fotopiroelétrica, especificamente, configuração SPPE. Além de realizar simulações analíticas dos gráficos de amplitude e fase dos sinais térmicos em função da frequência de modulação gerados para obter a propriedade térmica difusividade para uma amostra de óleo vegetal.

Palavras-chave: detecção ppe, óleo vegetal.

\section{INTRODUCTION}

The photothermal spectroscopy, particularly photopyroelectric detection is a technique based on the photothermal effect, consisting in heating a sample of nonradioactive de-excitation processes following the absorption of radiation.

The photopyroelectric technique directly measures the temperature oscillations in a medium with which it makes contact. A pyroelectric material varies in magnitude of the bias as a function of temperature variations. Pyroelectric sensors are such materials in form of films or sheets, which have their metallised surfaces, may act as current generators. 
In 1985, Mandelis and Zver developed the first photopyroelectric detection model for studying the thermal properties of solid materials (Mandelis and Zver, 1985), and it is known as Model SPPE (standard photopyroelectric) which consists of a beam of electromagnetic radiation modulated in a sample directly incident on a pyroelectric sensor. This configuration generally allows the determination of the thermal diffusivity of the sample investigated. Photopyroelectric detection in materials in the SPPE configuration was later extended to the generalized model (Chirtoc and Mihailescu, 1989) in which the detection electronics is taken into account.

The Model SPPE is a one-dimensional configuration and does not take into account the reflections that can occur on the surfaces of the sample and the sensor, nor influence of detection electronics in equations voltage and phase.

\section{METHODOLOGY}

The photopyroelectric detection comprises a set of at least three kinds of thermal processes that use models with excitation electromagnetic radiation modulated for determination of parameters for thermal material. The model developed in this work will be the model devised by SPPE Zver and Mandelis. Such a model consists of a system comprising four dimensional photopyroelectric means: Gas (g) sample (s), pyroelectric sensor (p) and a backing located behind the sensor (b).

The pyroelectric sensor is a device formed of a material that generates electric charges when itis heated. The sample thickness $L_{S}$ is irradiated by a monochromatic electromagnetic wave of wavelength $\lambda$, the intensity of which is modulated $I_{0}$ angular frequency $\omega$. The sample has $\beta_{s}(\lambda)$ optical absorption coefficient $(\lambda)$ and is in contact with the pyroelectric sensor thin film thickness $L_{p}$. The optical absorption coefficient and the sensorpyroelectric coefficient are $\beta_{s}(\lambda)$ and p, respectively. The sensor system + sample is supported on a base thickness considered very large compared to the thickness and $L_{s} L_{p}$. The electromagnetic wave incident uniformly illuminates the sample, or light absorption by the system sample + sensor increases the temperature of the pyroelectric sensor due to nonradioactive energy conservation into heat.

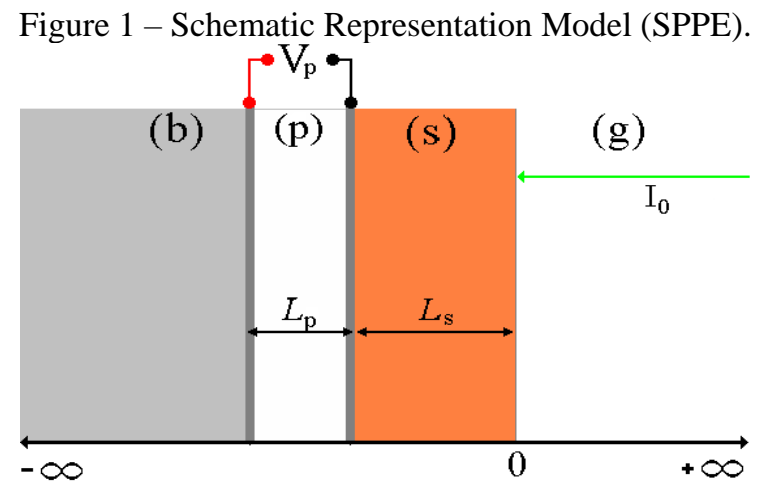


All media are analyzed individually applying the heat diffusion equation for each medium and obtaining the respective solutions of the equations of diffusion of heat. It is necessary to apply Fourier's law in each solution for obtaining the rate of change of the heat flow in each medium. The solutions of the diffusion equation and the change rates of heat flow for each medium are coupled due to continuity of heat flow and temperature at each of the interfaces. After application of boundary conditions, a set of six equations is obtained and, performing mathematical manipulations, it becomes possible to find the expressions amplitude and phase of the voltage pyroelectric, which are important parameter for determining the thermal diffusivity of the sample investigated by the system. In this simulation, soybean oil was used like the sample to be investigated. Researches into vegetable oils are also important for biodiesel production (Barrera et al., 2021).

The simulation was made from analytical equations of amplitude and phase for a specific configuration of sensor and sample thermally thick and optically opaque. Thus, we have the equation of complex voltage pyroelectric:

$$
V=\left[6,07\left(\frac{\eta P}{560+e_{s}}\right) \exp \left(-\sqrt{\frac{\pi f}{\alpha_{s}}} L_{s}\right)\right] \exp \left[\sqrt{\frac{\pi f}{\alpha_{s}}} L_{s}\right]
$$

\section{RESULTS AND DISCUSSION}

The Figure 2 shows the graphs obtained from the photopyroelectric complex equation: amplitude and phase signals versus modulation frequency for a sample of soybean oil. The amplitude signal is highlighted in blue while the phase signal is highlighted in red.

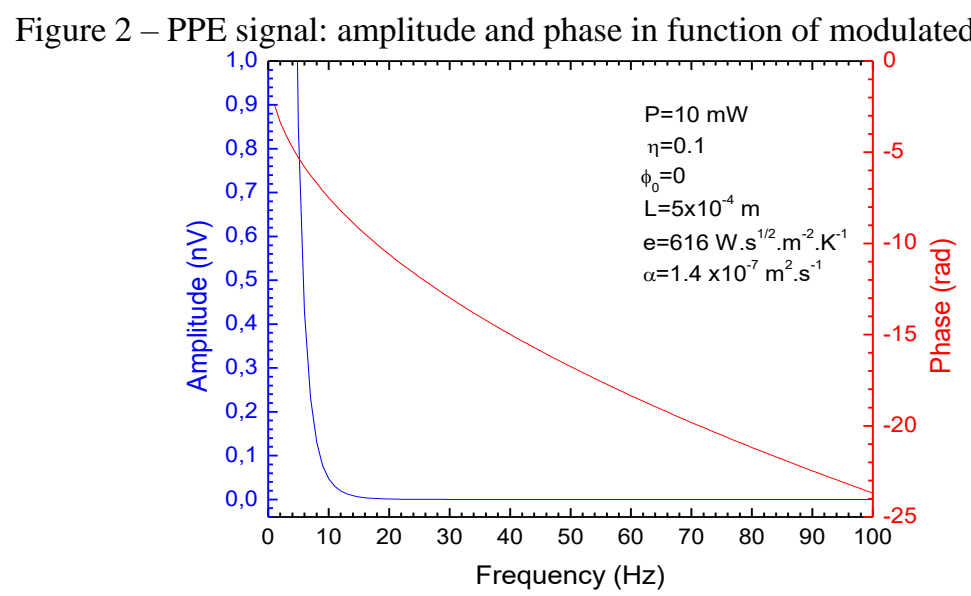

To obtain the simulated graphic is needed some experimental information, such as: power of the laser beam incident on the sample surface $(10 \mathrm{MW})$, sample thickness $\left(5 \times 10^{-4} \mathrm{~m}\right)$ and the initial 
signal amplifier (zero). We use the literature for the thermal properties of the sample (Dadarlat et al, 1996), while considering the value of 0.1 for the coefficient of performance of this same sample.

The graphs of simulations obtained from the photopyroelectric complex equation enable adjustment of experimental data to obtain the coefficient of thermal properties and efficiency samples for application in organic solar cells.

\section{THANKS}

This work received support from the Research Support Amazon Foundation (Fapespa). 


\section{REFERENCES}

Barrera, D. Alvarez; Parga, M. C. Chávez; Montoya, A. J. Castro. Latin American Journal of Development, Curitiba, v. 3, n. 5, p. 3217-3229, sep./oct. 2021. ISSN 2674-9297

Chirtoc, M.; Mihailescu, G. Theory of the photopyroelectric method for investigation of optical and thermal materials properties Physical Review B, 40 (14), 9606 (1989)

Dadarlat, D.; Gibkes, J; Bicanic, D.; Pasca, A. Photopyroelectric (PPE) measurement of thermal parameters in food products. Journal of Food Engineering, 30, 155 (1996)

Mandelis, A.; Zver, M. Theory of photopyroelectric spectroscopy of solids. Journal of Applied Physics, 57, $4421(1985)$ 